\title{
Infrared Low Temperature Turbine Vane Rough Surface Heat Transfer Measurements
}

R.J. Boyle, C.M. Spuckler, B.L. Lucci, and W.P. Camperchioli Glenn Research Center, Cleveland, Ohio

Prepared for the

45th International Gas Turbine and Aeroengine Technical Congress sponsored by the American Society of Mechanical Engineers

Munich, Germany, May 8-11, 2000

National Aeronautics and

Space Administration

Glenn Research Center 


\section{Acknowledgments}

The authors wish to thank Dr. James Van Fossen for the two-dimensional computer code used for the analysis of the conduction losses.

Available from

NASA Center for Aerospace Information 7121 Standard Drive

Hanover, MD 21076

Price Code: A03
National Technical Information Service 5285 Port Royal Road Springfield, VA 22100

Price Code: A03 


\title{
INFRARED LOW TEMPERATURE TURBINE VANE ROUGH SURFACE HEAT TRANSFER MEASUREMENTS
}

\author{
R.J. Boyle, C.M. Spuckler, B.L. Lucci and W.P. Camperchioli \\ National Aeronautics and Space Administration \\ Glenn Research Center \\ Cleveland, Ohio 44135
}

\begin{abstract}
Turbine vane heat transfer distributions obtained using an infrared camera technique are described. Infrared thermography was used because non-contact surface temperature measurements were desired. Surface temperatures were $80^{\circ} \mathrm{C}$ or less. Tests were conducted in a three vane linear cascade, with inlet pressures between 0.14 and $1.02 \mathrm{~atm}$., and exit Mach numbers of 0.3 . 0.7 , and 0.9 . for turbulence intensities of approximately 1 and $10 \%$. Measurements were taken on the vane suction side, and on the pressure side leading edge region. The designs for both the vane and test facility are discussed. The approach used to account for conduction within the vane is described. Midspan heat transfer distributions are given for the range of test conditions.
\end{abstract}

\section{Nomenclature}

$\begin{array}{ll}A & - \text { Area of heat surface } \\ C_{f} / 2 & - \text { Friction factor } \\ C_{x} & - \text { Axial chord } \\ D & - \text { Leading edge diameter } \\ F & - \text { Local-to-average heat flux } \\ f & - \text { Fraction of radiant energy } \\ F r & - \text { Frossling number, } N u_{\mathrm{D}} / \sqrt{R \epsilon_{\mathrm{D}}} \\ G r & - \text { Grashof number } \\ h & - \text { Roughness height } \\ I & - \text { Current } \\ K & - \text { Thermal conductivity } \\ N u & - \text { Nusselt number } \\ P r & - \text { Prandtl number } \\ q & - \text { Heat flux per unit area } \\ R e & - \text { Reynolds number } \\ S t & - \text { Stanton number } \\ s & - \text { Surface distance }\end{array}$

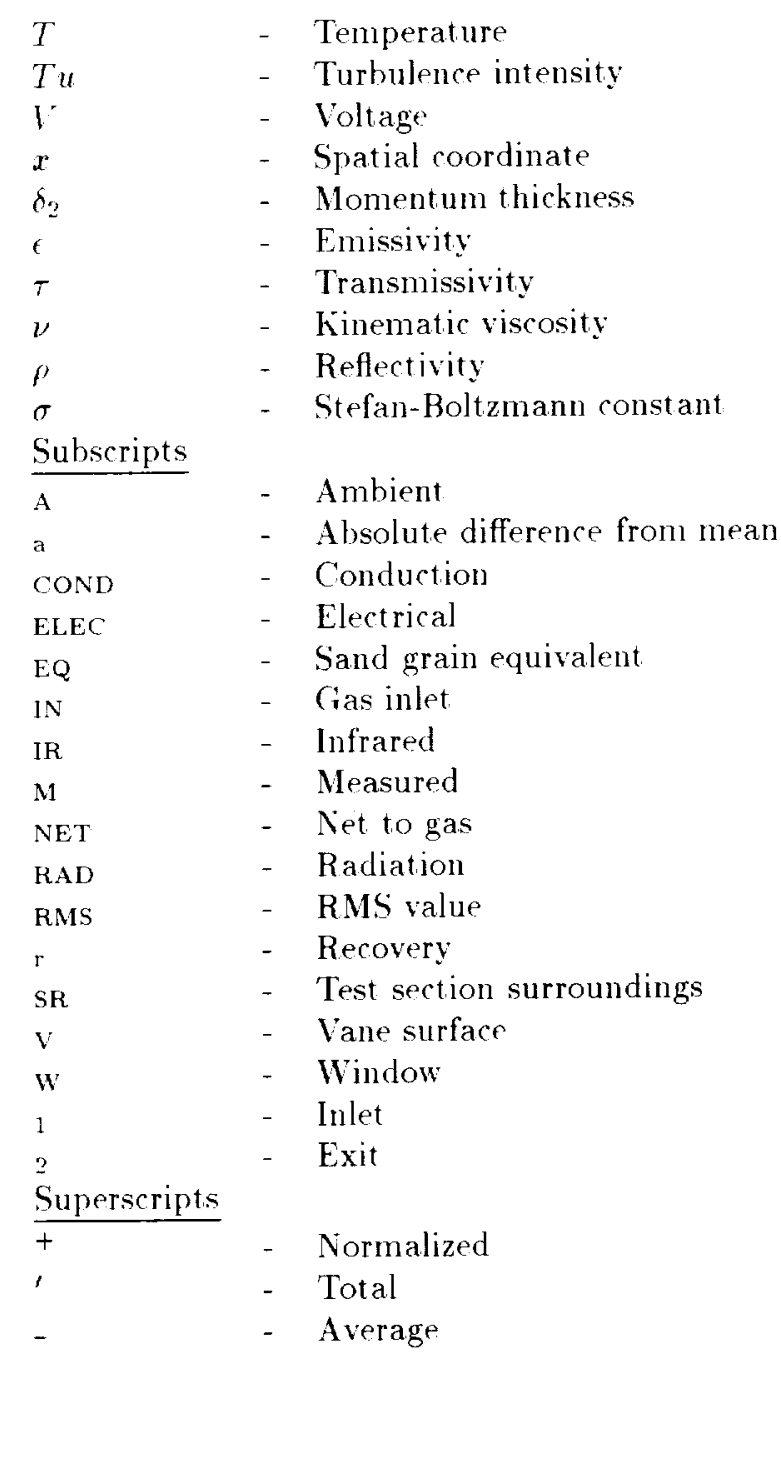


Table I. 'Test vane characteristics

\section{INTRODUCTION}

It is important to understand the effects of surface roughness on turbine blade heat transfer. Surface roughness is expected to increase blade surface heat transfer. Whether blade temperature increases, depends on the nature of the surface roughness. If the surface roughness results from low thermal conductivity material deposited onto the blade surface, the heat load, and therefore blade temperature, may decrease due to the thermal resistance of the deposition layer. If surface roughness results from material erosion, understanding blade heat transfer becomes more critical, since blade strength decreases, and average blade temperature increases due to higher gas side heat transfer.

Experimental heat transfer for rough surface turbine blades have been reported by several investigators. Dunn et al.(1994), and Blair(1994) used different techniques to measure rotor heat transfer in rotating facilities. Tarada(1987). Tarada and Suzuki(1993). and Abuaf et al.(1997) reported measurements of vane heat transfer for rough surfaces. While these tests indicated higher heat transfer for rough surfaces, the heat transfer ratio between rough and smooth surfaces varied considerably. This may have been due to differences in Reynolds number as well as roughness characteristics.

To help clarify the consequences of surface roughness, a program to measure the heat transfer on a rough surface turbine vane was undertaken. It was felt that true surface temperatures, as opposed to temperatures between the roughness and the freestream. should be measured. Also, it was felt important to generate the heat flux at the vane surface, so as not to introduce an insulating layer between the heater and the vane surface. Temperature differences across an insulating layer of unknown thickness would adversely affect the measurements. especially at higher Reynolds numbers. These requirements led to a test configuration in which the rough surface was used to generate the heat flux, and temperatures were measured using an infrared camera. An infrared measurement technique was used because this technique does not rely on contact with the test surface, and does not disturb the surface profile. The infrared camera system generates a temperature map of the portion of the vane surface seen by the camera. Heat transfer measurements using an infrared camera have been reported by several investigators. Sargent ot al.(1998). Baldauf et al.(1999), Johnston et al.(1999). as well as Sweeney and Rhodes(1999) used infrared cameras to measure different aspects of film cooling heat trausfer.

\begin{tabular}{|l|l|}
\hline Axial chord, $C_{\mathrm{x}}$ & $4.445 \mathrm{~cm}$ \\
True chord, $C / C_{\mathrm{x}}$ & 2.25 \\
Pitch-to-axial chord ratio & 1.86 \\
Span-to-axial chord ratio & 4.86 \\
Heated span-to-axial chord ratio & 2.36 \\
Flow turning & $80^{\circ}$ \\
\hline
\end{tabular}

The test facility allowed accurate flow measurenents over a range of Reynolds numbers that varied by more than a factor of twenty. A single vane was tested. Consequently, while the physical vane roughness remained constant, the surface went from being nearly hydraulically smooth to fully rough as the Reynolds number was varied. While the lower Reynolds numbers tests are lower than those for a typical high pressure turbine application, they are approached in low power engine applications.

The purposes of the work reported herein are to show the effects of surface roughness on heat transfer, and to quantify when surface roughness is important. A rompanion paper, Boyle et al.(2000) describes an analysis useful for predicting rough surface turbine heat transfer.

\section{DESCRIPTION of EXPERIMENT}

The measurements were taken in the three vane linear cascade illustrated in figure 1 . The center vane was the test vane. Air entered the test section at pressures between 0.14 and slightly greater than 1 atmospheres. The air was at ambient temperature. Valves between the test section and a low pressure altitude exhaust section were adjusted to maintain the desired vane exit isentropic Mach number. Periodicity was achieved by adjusting the tailboards. Further details of the test configuration are given by Boyle et al. (1998). This reference documented the inlet turbulence intensity and length scale for the range of Reynolds and Mach numbers used in the present work. Test were done with and without the turbulence grid in place.

The vane was heated, and when steady state was achieved, vane surface temperatures were measured using an infrared canlera system. The Inframetrics 600 camera was operated in the open mode, $(3$ tol $2 \mu \mathrm{m})$. and used a liquid nitrogen cooled detector. The output from the camera and its associated computer was the temperature at each pixel in an array. The pixel array size was 364 by 208 . The digital temperature output of the camera system was verified using a black body of known temperatures. 


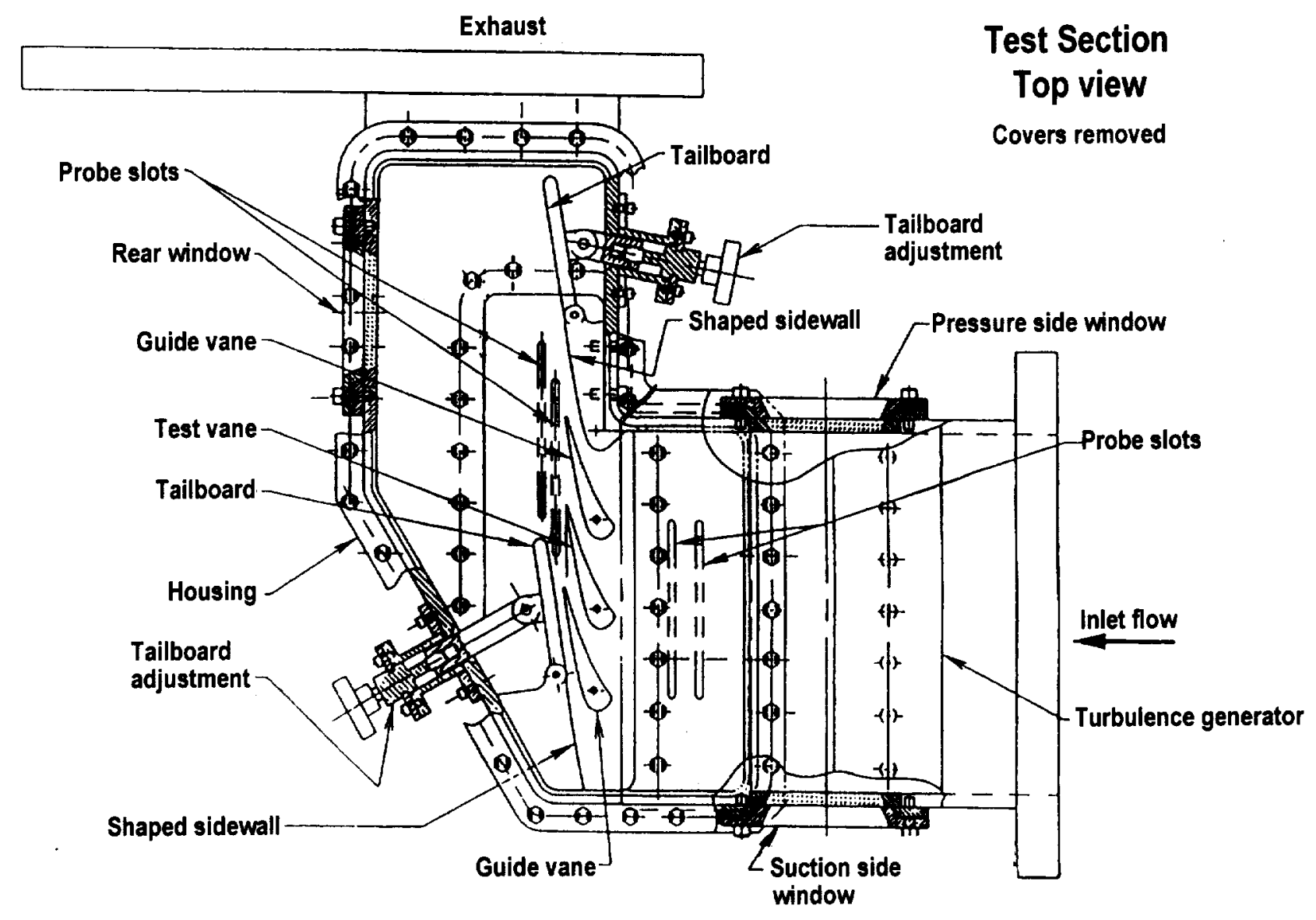

Fig. 1 Overall view of test section.

Both the inside and outside of the test section were painted with a flat black paint to reduce reflected thermal energy. This was done to minimize stray thermal energy onto the detector. The vane was viewed through each of the the three window locations shown in figure 1. A ZnSe window, mounted flush with the inside surface, was used. The ZnSe window had a diamondlike coating to increase its surface hardness, and thus reduce the effects of abrasion from high speed flows. The coating was applied using the method described by Banks and Rutledge(1982).

Data were obtained for a range of Reynolds and Mach numbers, and two inlet turbulence intensities. For each test there were three views of the vane. The forward portion of the pressure surface was viewed through the pressure side window. The forward portion of the suction surface was viewed through the suction side window, and the rear portion of the suction surface was viewed through the rear window. A front faced, highly reflecting, mirror was used when viewing through the rear window. A region of the suction surface forward of the throat was not visible to the infrared camera.
However, enough of the vane surface was visible that the effects of surface roughness could be quantified.

Figure 2 illustrates the test vane construction, and table I gives the vane geometric parameters. The intent of the test was to make midspan measurements, away from the endwalls Consequently; a high aspect ratio of 4.86 was specified, which gives a span-to-true chord ratio of 2.16. An aluminum vane was used, and much of the middle portion was removed. A spar was left in this region to provide rigidity to resist the pressure loads at high Mach and Reynolds numbers. Only the suction surface of the vane and the pressure surface near the leading edge were available for heat transfer measurements. A copper bus bar, shaped to the vane profile was attached to each end of the opening. The bus bars were insulated from the aluminum vane, and had copper rods extending through the entire test section to provide electrical power. A high strength, but low thermal conductivity foam material, Rohacell 300. was inserted between the copper bus bars. It was also shaped to the vane profile. Roughness was achieved by 


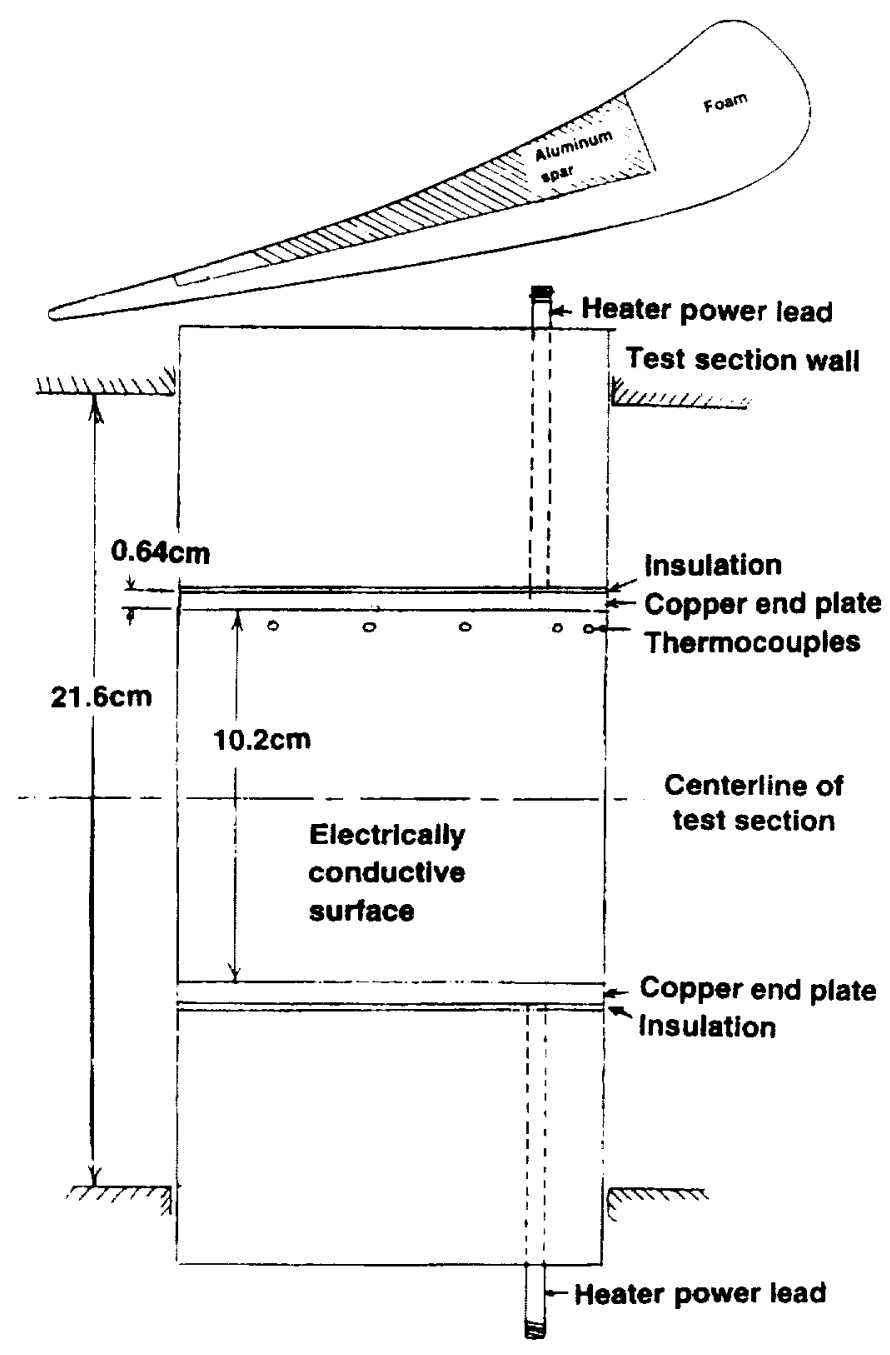

Fig. 2 Construction of heat transfer vane.

not smoothing the foam surface. The foam was securely bonded to the copper bus bars. After appropriate masking, an electrically conducting silver paint was sprayed onto the vane surface. This created an electric circuit hetween the bus bars. As shown in figure 2 the forward portion of the pressure surface, all of the suction surface, and a small part of the pressure surface trailing edge region were painted. At room temperature the resistance of the heater was $0.07 \mathrm{ohms}$.

In addition to instrumentation to measure the heater voltage and current, nine Type $\mathrm{E}$ thermocouples were attached to the test section. Three thermocouples were attached to the aluminum spar near midspan. They were located between the foam and aluminum. Six thermocouples were placed on the vane surface at different locations close to the upper bus bar. They were insulated from the heater surface, and were attached with an epoxy covering. Five thermocouple locations are
Table II. Average roughness properties

\begin{tabular}{|r|r|r|}
\hline Property & Value & Normalized by $C_{\mathrm{x}}$ \\
\hline$R_{\mathrm{RMS}}$ & $111 \pm 18 \mu \mathrm{m}$ & $25 \pm 4 \times 10^{-4}$ \\
$R_{\mathrm{a}}$ & $92 \pm 15 \mu \mathrm{m}$ & $21 \pm 4 \times 10^{-4}$ \\
Skewness & $-0.58 \pm 0.34$ & \\
hurtosis & $-0.42 \pm 0.49$ & \\
\hline
\end{tabular}

shown in figure 2. The sixth themocouple is on the vane pressure side. The surface thermocouples could not be used for an in situ calibration of the infrared camera. Because the surface thermocouples were secured using an epoxy covering they did not read the surface temperature. The difference between the thermocouple and infrared temperatures varied with the flow condition. The thermocouple locations were known. and because the infrared temperature differed from the thermocouple's surrounding temperature, they were used to locate the pixel coordinates onto the vane surface. The thermocouple locations were especially visible during transient cool down.

Roughness Characteristics. Data from six profilometer traces were used to determine the roughness characteristics of the heated surface. Each trace was approximately $1 \mathrm{~cm}$ in length. A summary of the analysis of these traces is presented in table II. The rms roughness averaged slightly over 100 micrometers, while the average absolute roughness height was 92 micrometers. The one sigma variation in these parameters anong the six traces was approximately $16 \%$. The skewness showed considerable variation among the traces, but was always negative. Negative skewness means that the area above the meanline exceeds the area below the meanline. The average kurtosis was negative, with only one trace evidencing a positive value. According to Dagnall(1986) a negative kurtosis indicates a bumpy, rather than spiky surface profile.

The roughness height of 111 micrometers corresponds to $h_{\mathrm{RMS}} / C_{x}$ of 0.0025 , or $h_{\mathrm{RMS}} / C$ of 0.001 . Kind et al.(1998) reported aerodynamic effects for rotors having hands of roughness in the height-to-chord range of 0.0021 to 0.0063 . Aerodynamic tests for uniformly covered sand grain roughness in the range of $h_{\mathrm{EQ}} / C$ between 0.001 and 0.01 have been reported by Bammert and Stanstede(1972,1976) and by Boynton et al.(1992).

The degree to which surface roughness affects the flow and heat transfer is determined by its value in wall normalized coordinates. The maximum normalized roughness height. $h_{\mathrm{EQ}}^{+}$. was estimated using the procedure proposed by Boyle and Giel(1995) to estimate the maximum near wall grid spacing prior to a CFD calculation. 


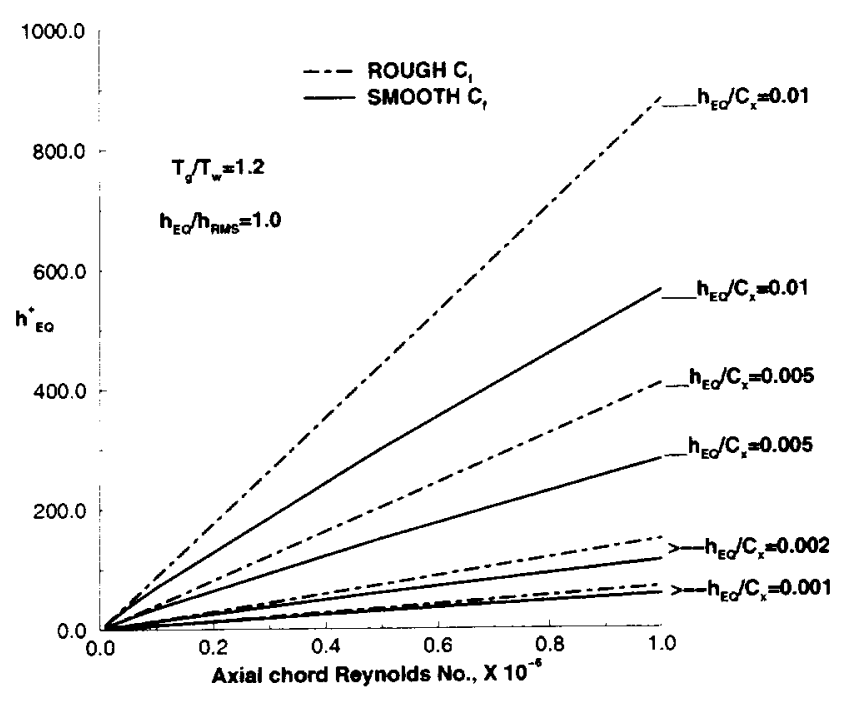

Fig. 3 Estimated maximum equivalent roughness height, $\mathrm{h}_{\mathrm{EQ}}^{+}$

$h_{\mathrm{EQ}}^{+}=0.17 \frac{h_{\mathrm{RMS}}}{C_{x}} \sqrt{\frac{\left(C_{f}\right)_{\mathrm{ROL} G \mathrm{H}}}{\left(C_{f}\right)_{\mathrm{SMOOTH}}}}\left(\frac{h_{\mathrm{EQ}}}{h_{\mathrm{RMS}}}\right)\left(\frac{T_{\mathrm{IN}}}{T_{\mathrm{V}}}\right)^{1.5} R f^{0.9}$

Where Re is a Reynolds number based on axial chord. $C_{r}$. To maximize $h_{\mathrm{EQ}}^{+}, R c$ is taken as the exit Reynolds number. Re.2. The ratio of $h_{\mathrm{EQ}}$ to $h_{\mathrm{R} . \mathrm{s}}$ was estimated to be about two for the vane tested. Figure 3 shows $h_{\mathrm{EQ}}^{+}$as a function of $R \epsilon_{2}$ and $h_{\mathrm{EQ}} / C_{\mathrm{x}}$ for two friction factors. The curves labeled SMOOTH are for a $C_{f}$ ratio of one. The curves labeled ROUGH are for for fully rough flow using the relationship for $C_{f} / 2$ given by Kays and Crawford(1980)

$$
\frac{C_{f}}{2}=\frac{0.168}{\left[\ln \left(864 \delta_{2} / h_{\mathrm{EQ}}\right)\right]^{2}}
$$

This figure shows that $h_{\mathrm{EQ}}^{+}$increases almost linearly with Reynolds number and with the roughness height. For $h_{\mathrm{EQ}}^{+}>70$, the ROCGH curve is the appropriate curve to use for estimating $h_{\mathrm{EQ}}^{+}$. For $5<h_{\mathrm{EQ}}^{+}<70$, the appropriate value for $h_{\mathrm{EQ}}^{+}$lies between the two curves. Fortunately, in this region the differences between the SMOOTH and ROCiGH curves are small. Since the equivalent height ratio was estimated to be about two, and $h_{\mathrm{RMS}} / C_{x}=0.0025$. the maximum equivalent height at each Reynolds number was expected to be on the ROIGH $C_{f}$ line for $h_{\mathrm{RMS}} / C_{x}=0.005$. At high Reynolds numbers the maximum $h_{\mathrm{EQ}}^{+}$was expected to be given by the dashed curve for $h_{\mathrm{EQ}} / C_{x}=0.005$. As the Reynolds number decreases the maximum $h_{\mathrm{EQ}}^{+}$was expected to eventually be given by the solid line at the same value for $h_{\mathrm{EQ}} / C_{r}$.

\section{ANALYSIS of DATA}

The measured temperatures were corrected to give the true surface temperature. This correction accounts for the emissivity of the vane surface. the emissivity and temperature of the surroundings, and the ambient temperature. The IR camera system measured the true temperature of a black hody when the emissivity was one. The measured temperature, $T_{\mathrm{M}}$, is determined from a heat balance on the infrared camera receiver. The energy incident on the detector is less than the emitted energy. The camera system cuts off energy at wavelengths above 12 microns. (amera temperatures were determined by energy in the 3 to 12 micron band. Because of the small measured temperature differences. and the wide wavelength band, the variation in the fraction of energy incident on the detector was neglected. The energy on the detector is $q_{1 \mathrm{R}}=f(3.12)_{\mathrm{M}} \sigma T_{\mathrm{N}}^{4}$. Where $f(3,12)$ is the fraction of available radiant energy in the 3 to 12 micron band, and is a function of temperature. In actuality the heat flux is given by:

$$
\begin{aligned}
q_{\mathrm{IR}}=\sigma\left(\tau_{\mathrm{W}}\left(\epsilon_{\mathrm{V}} f(3,12) \cdot T_{\mathrm{V}}^{4}+\rho_{\mathrm{V}} \epsilon_{\mathrm{SR}} f(3.12)_{\mathrm{SR}} T_{\mathrm{SR}}^{4}\right)+\right. & \\
& \left.\left(1-\tau_{\mathrm{W}}\right) \epsilon_{\mathrm{A}} f(3,12)_{\mathrm{A}} T_{\mathrm{A}}^{4}\right)
\end{aligned}
$$

The fraction of available energy, $f(3.12)$, was assumed constant. (alculations showed that, because of the small temperature differences. no significant error was introduced by assuming $f(3,12)$ constant. Equating the two expressions for the heat flux gives the vane temperature as:

$$
T_{\mathrm{V}}^{4}=\frac{T_{\mathrm{M}}^{4}-\left(1-\tau_{\mathrm{W}}\right) \epsilon_{\mathrm{A}} T_{\mathrm{A}}^{4}-\tau_{\mathrm{W}} \rho_{\mathrm{V}} \epsilon_{\mathrm{SR}} T_{\mathrm{SR}}^{4}}{\tau_{\mathrm{W}} \epsilon_{\mathrm{V}}}
$$

At each point on the vane the Nusselt number is calculated from:

$$
N u=\frac{q_{\mathrm{NET}} C_{\mathrm{x}}}{\left(T_{\mathrm{V}}-T_{\mathrm{r}}\right) h}
$$

The local adiabatic recovery temperature, $T_{\mathrm{r}}$, was determined from the inlet total temperature. $T_{\mathrm{IN}}^{\prime}$, and the surface pressure distribution. The surface pressures were determined from a two-dimensional Navier-Stokes analysis,(Chima, 1996).

The vane local net heat flux was calculated from:

$$
q_{\mathrm{NET}}=q_{\mathrm{ELEC}}-q_{\mathrm{COND}}-q_{\mathrm{RAD}}
$$


Null tests. If the resistivity of the heater were uniform. $q_{\text {ELEC }}$ would be given by: $q_{\text {ELEC }}=I \cdot 1 / A=\bar{q}$. However, measurements indicated that the heat flux was not uniform. so that the ratio of local-to-average heat flux. $F$. had to be determined. Tests were done where the heat transfer was known to be nearly uniform over the vane surface. For these tests heat transfer was by free, not forced convection. For turbulent free convection the heat transfer is independent of the streamwise location. For turbulent flow over a vertical flat plat Burmeister(198:3) gives a correlation for the local Nusselt number as:

$$
N u_{r}=0.1\left(G r_{x} P r\right)^{1 / 3}
$$

Here. $x$ is the spanwise distance. Since $G r_{x}=g x^{3}\left(T_{V}-\right.$ $\left.T_{1 N}^{\prime \prime}\right) /\left(\nu^{2} T_{\mathrm{IN}}^{\prime}\right), N u$ is independent of $x$, but depends on $T_{\mathrm{V}}-T_{\mathrm{IN}}^{\prime}$ to the one-third power. For this test condition:

$\frac{q_{\mathrm{ELEC}}}{\bar{q}}=\digamma=\frac{\left(\frac{T_{\mathrm{v}}-T_{i \mathrm{~S}}^{\prime}}{\overline{T_{\mathrm{V}}}-T_{\text {iN }}^{i}}\right)^{4 / 3}+q_{\mathrm{COND}} / \overline{q_{\mathrm{NET}}}+q_{\mathrm{RAD}} / \overline{\overline{\mathrm{NET}}}}{1+\overline{q_{\mathrm{COND}}} / \overline{q_{\mathrm{NET}}}+\overline{q_{\mathrm{RAD}}} / \overline{q_{\mathrm{NET}}}}$

At each point on the vane surface $q_{\text {COND }}$ is evaluated from the temperature distribution around the vane. $\overline{4 C O N D}$ is evaluated using the average surface temperature and measured metal temperatures.

$q_{\mathrm{KAI}} / \overline{q_{\mathrm{NET}}}$ is approximated by:

$$
\frac{q_{\mathrm{HAD}}}{\overline{\text { TET }}}=\frac{\overline{\overline{\mathrm{RAD}}}}{\overline{q_{\mathrm{NET}}}}\left(\frac{T_{\mathrm{V}}-T_{\mathrm{SR}}}{\overline{T_{\mathrm{V}}}-T_{\mathrm{SR}}}\right)
$$

At each point on the circumference of the vane $q_{C O N D}$ was assumed equal to $\overline{q C O N D}$. $\overline{q C O N D}$ was evaluated using a two-dimensional conduction analysis. The analysis used the average surface temperature and measured metal spar temperature.

Flow tests. For test with flow over the vane the local Nusselt is given by:

$$
v_{u}=\frac{\left(F I I / A-q_{C O N D}-q_{\mathrm{RAD}}\right) C_{x}}{\left(T_{\mathrm{V}}-T_{\mathrm{r}}\right) K}
$$

The term qcovn was evaluated for each test using the same two-dimensional conduction analysis as for the null test. In the flow test the heat transfer distribution was not uniform, but varied with circumferential location. The local value of $F$ was found from the null test.

Since the flow in the cascade is two dimensional, the spanwise average Nusselt number is of interest. This value was obtained by integrating in the spanwise direction. At each distance around the vane, the heat
Table III. Summary of test conditions.

\begin{tabular}{|c|c|c|}
\hline & \multicolumn{2}{|c|}{ Ideal Axial chord Re No. $\times 10^{-6}$} \\
\hline$H_{2}$ & Inlet & Exit \\
\hline 0.3 & 0.0055 & 0.011 \\
& 0.0086 & 0.061 \\
& 0.0157 & 0.101 \\
& 0.0278 & 0.202 \\
& 0.0405 & 0.303 \\
\hline 0.7 & 0.0317 & 0.236 \\
& 0.0521 & 0.394 \\
& 0.0792 & 0.590 \\
\hline 0.9 & 0.0307 & 0.240 \\
& 0.055 .5 & 0.444 \\
& 0.0826 & 0.66 .5 \\
\hline
\end{tabular}

transfer coefficient was averaged over a fraction of the spanwise distance. When the fraction was very small the result was the midspan values. However, these values, in addition to being noisy, were very sensitive to the spanwise alignment of the infrared camera images. Averaging over a $40 \%$ of the heated span gave less alignment sensitivity and less point-to-point variations in the heat transfer.

The uncertainty in the Nusselt number was estimated to be about $15 \%$ over most of the vane surface. The uncertainty in the infrared camera measurements was better than $2^{\circ} \mathrm{C}$, and the camera resolved differences of less than $0.2^{\circ} \mathrm{C}$. The infrared camera uncertainty was minimized be verifying the camera system output for a calibrated black body, and by comparing the pre-test surface temperatures with the inlet thermocouple readings. The maximum uncertainty occured at the minimum surface-to-gas temperature difference. The maximum surface temperature of $80^{\circ} \mathrm{C}$ was set based on the temperature capability of the foam material. This temperature occurs at the minimum Nusselt numbers. The large variation in Nusselt numbers meant that at high Nusselt numbers the surface-to-gas temperature difference was much less than $60^{\circ} \mathrm{C}$. The estimate was made by assigning uncertainties to all of the variables used in the data reduction, and doing the analysis repetitively. The local heat flux was determined by properties in addition to the heater voltage and current. The uncertainty analysis treated the determination of $F$ as a part of the analysis, and not as an independent quantity. This has the beneficial effect of reducing heat transfer uncertainty due to some independent variables, such as thermal conductivity. The one region where there is a higher uncertainty in heat transfer is the very rear portion of the suction surface. At the design of the test vane the assumption was made that the heat transfer rate at the very rear of the suction and pressure surfaces would be the same. This was done on the basis of CFD analyses. However, the experiment was unable to 


\section{Pressure side}

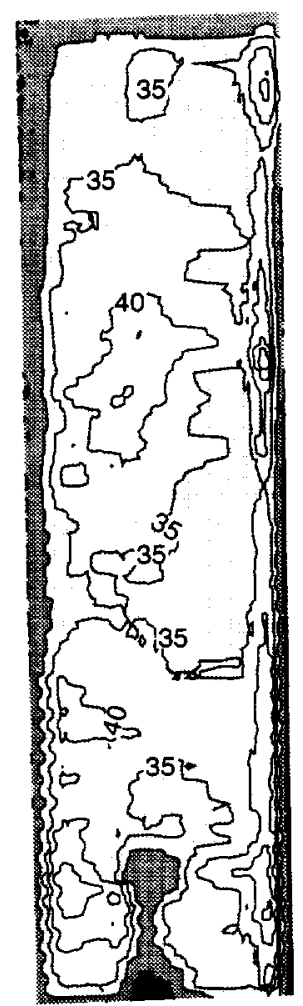

\section{Suction - Front}

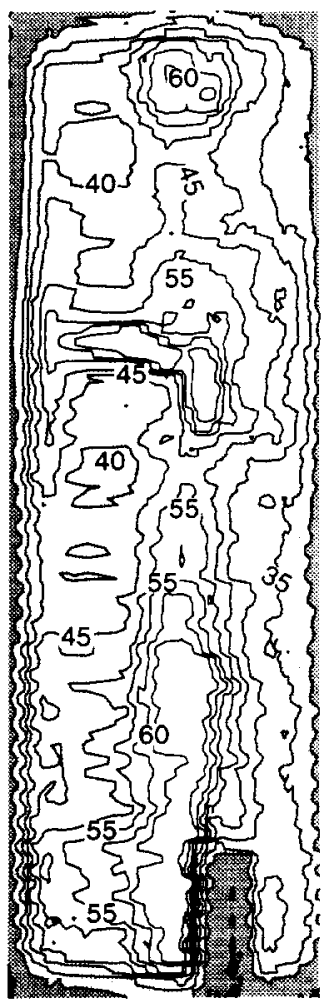

\section{Suction - Rear}

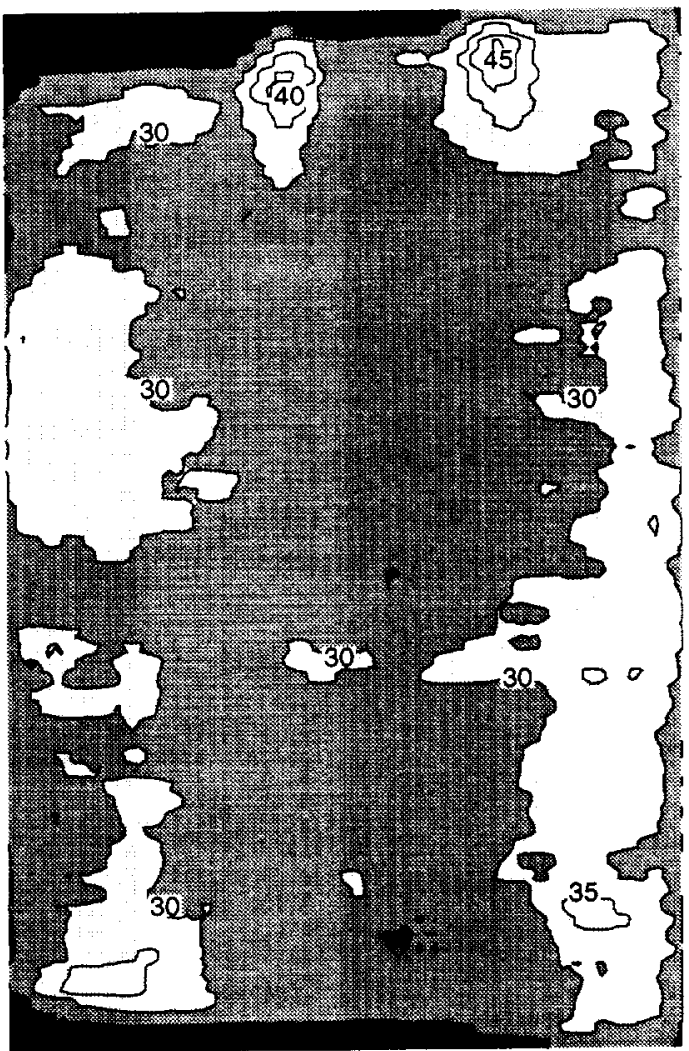

Fig. 4 Temperatures recorded by infrared camera. ${ }^{\circ} \mathrm{C}$.

verify this assumption under flow conditions. A temperature difference across the vane near the trailing edge would affect low Nusselt number measurements more than those at higher Nusselt numbers.

There was also a positional uncertainty due to the alignment of the camera. This uncertainty was estimated to be less than $0.05 C_{\mathrm{x}}$.

\section{EXPERIMENTAL RESULTS}

Table III shows the range of test conditions for which data were obtained. Data were obtained at three isentropic exit Mach numbers for a range of inlet total pressures. The Reynolds numbers in this table are based on axial chord, and varied by nearly a factor of 15 over the range of test conditions. At each test point, data were obtained for two inlet turbulence intensities. Boyle et al.(1998) reported that the turbulence intensity measured 1.14 axial chords upstream of the leading edge was between 13 and $15 \%$ over the range of test conditions. Air was blown through the grid to achieve a pitchwise uniformity in turbulence intensity.
The results obtained for the entire heated span at a single test condition will be discussed first. This is followed by a discussion of the midspan results for all of the test cases.

Full span results. Figures 4 through $T$ illustrate full span results for a typical test case. The case is for $R \epsilon_{2}=0.394 \times 10^{6}, M_{2}=0.7$, with the turbulence grid . The temperatures recorded by the infrared camera are given, followed by the calculated vane surface temperatures. Next, the surface Nusselt numbers are shown. The Nusselt number distribution is shown when the heat generation is assumed uniform, and this is followed by the Nusselt number distribution calculated using the the local heat generation determined from the null test. Figure 4 shows the infrared camera temperature distribution for the vane for a typical test case. The views as seen through each of the three windows are shown. The heated portion of the pressure surface is followed by the forward portion of the suction surface, and ends with the rear part of the suction surface. Moving from left to right in the pressure side view shows the forward part of the pressure surface, the leading edge region, and a small portion of the suction surface. 


\section{Pressure side}

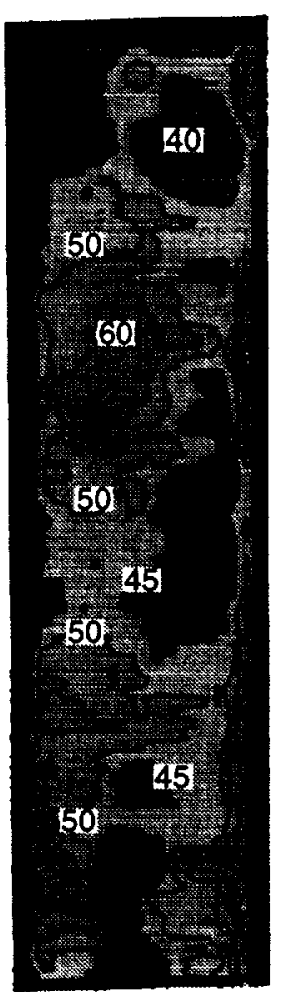

\section{Suction - Front}

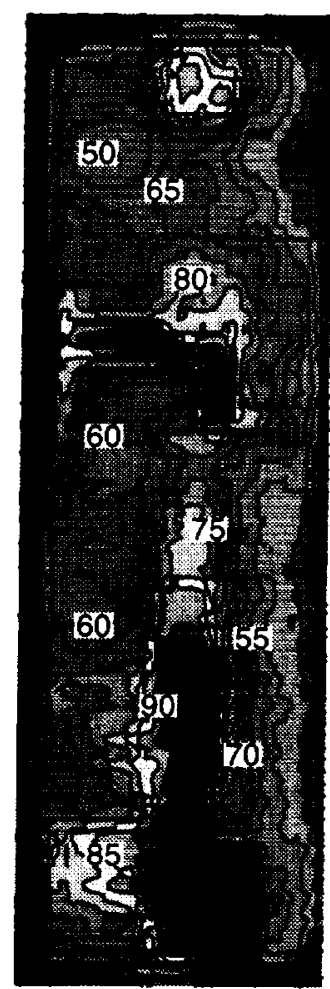

\section{Suction - Rear}

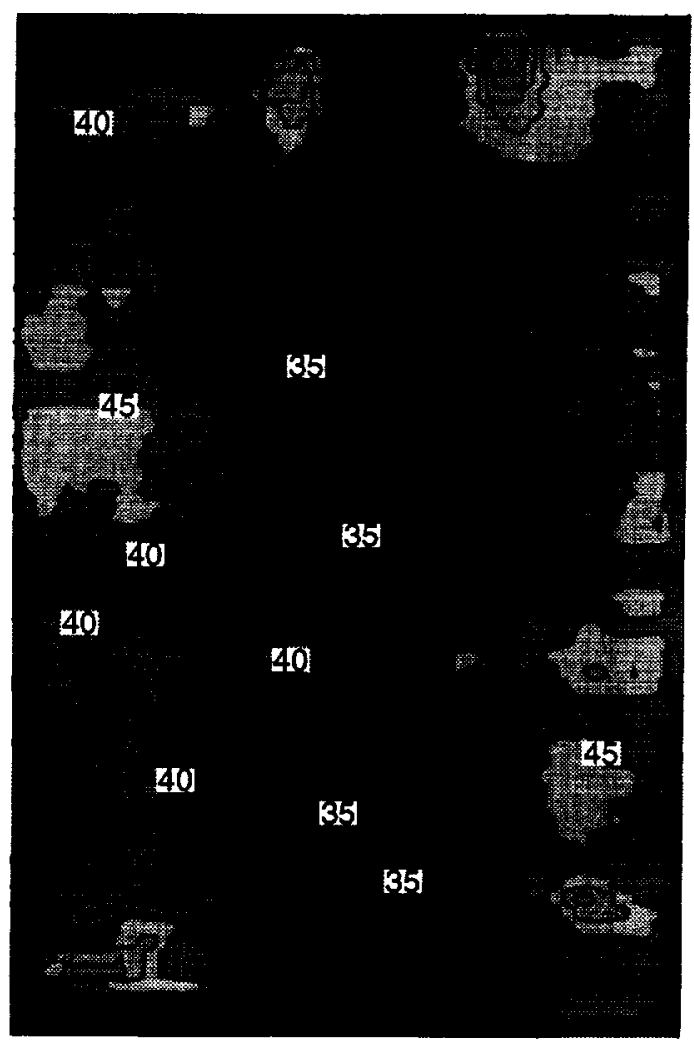

Fig. 5 Calculated surface temperatures ${ }^{\circ} \mathrm{C}$.

Similarly, the forward view of the suction side shows a small portion of the pressure side, the leading edge and the front portion of the suction side. The rear suction side view begins near the throat region. and continues to the trailing edge. The first two parts overlap in the leading edge region. In the lower region of the two front views there are apparent discontinuities in the surface temperatures. These are the result of sensor probes in the line of sight between the vane and the camera, and were left in the camera's view to help align the images. The spanwise temperature variation is due to heat generation non uniformity and variations in surface roughness. In each view, near the blade top, there are small islands of large temperature gradients. These islands, labeled $35,60.40$, and $45^{\circ} \mathrm{C}$, correspond to thermocouple locations. A high degree of spatial resolution is visible in these figures. The suction surface rear view shows cold temperatures in the middle of the surface distance. Since this is where the insulating foam is thinest, it is reasonable to suspect that this is a region of high conductive heat lass. While the conductive heat loss to the cold aluminum spar can be significant in this region, this is also a region of lower than average heat generation. If conduction were the cause of the cold temperatures, its relative importance decreases as the Reynolds number and external heat transfer increase. The temperatures would become more uniform at high convective heat transfer rates. However, this was not the case, and using measured values for the foam thermal conductivity showed that the generated heat flux in this region was lower than average.

Figure 5 shows the calculated temperatures using the measured infrared camera temperatures, the surrounding temperature, the ambient temperature, the vane emissivity, and the window transmissivity. At the two higher Mach numbers the surrounding temperature varied from view to view. It was calculated as the adiabatic temperature seen on the adjacent vane. Even though the silver paint has a low emissivity on a smooth surface, measurements of the rough vane surface gave an emissivity of approximately 0.75 . The measured emissivity was influenced by several factors. Considerable 


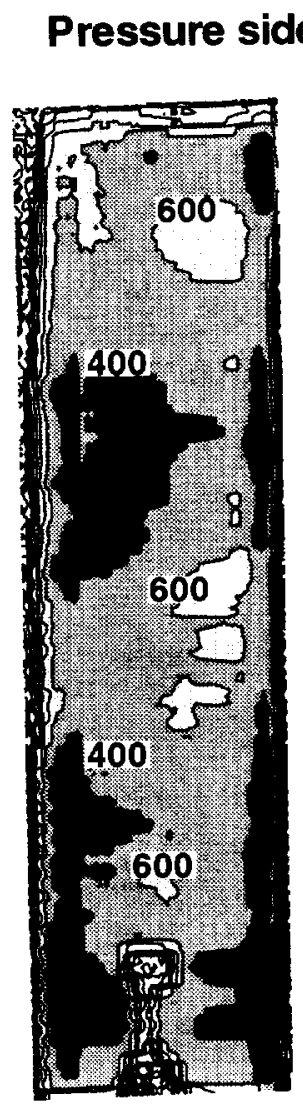

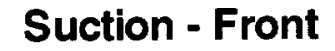

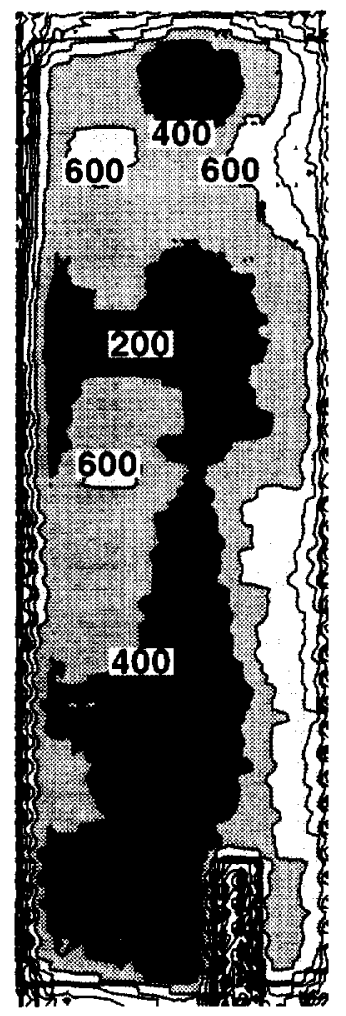

\section{Suction - Rear}

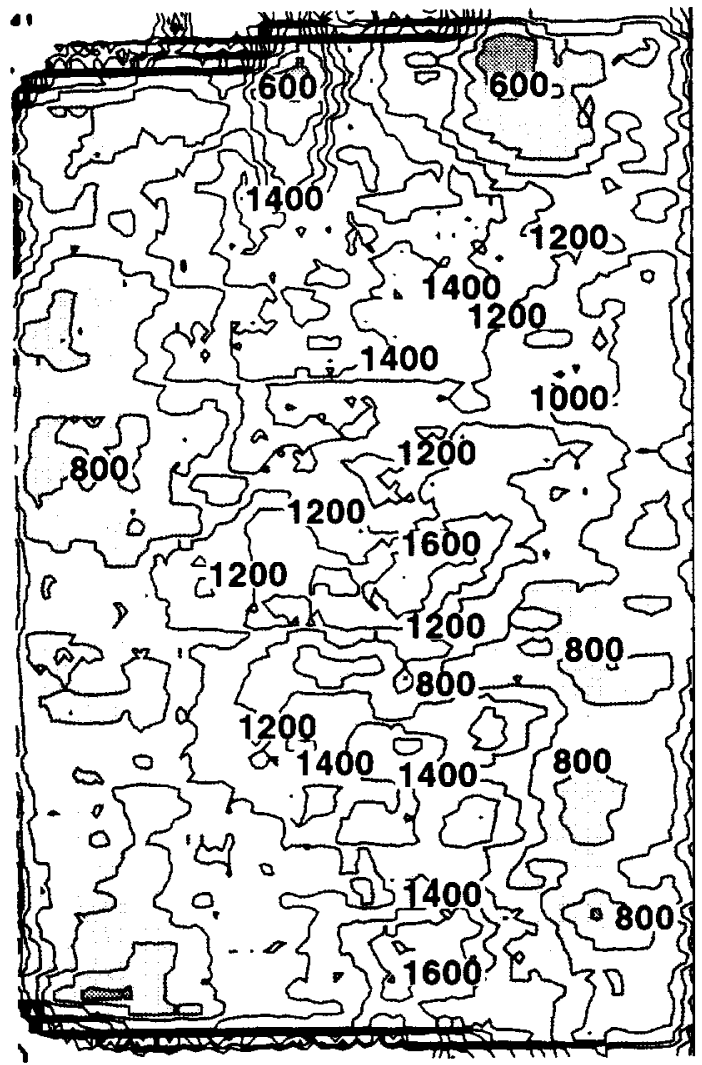

Fig. 6 Nusselt number - uniform heat flux.

variations in emissivity were observed, and the effect of a variation in emissivity is discussed. The transmission of the $\mathrm{ZnSe}$ window was found to be approximately 0.7 , when viewing at a near normal angle. This transmissivity was consistent with the calculated value using the index of refraction for the material. When the vane was viewed through the rear window the transmissivity was reduced to 0.65 to account for both the mirror reflectivity and the highly oblique angle to the window. There is a temperature discontinuity when the camera views a surface other than the heated one. This could be either an adjacent vane or the unheated portion of the test vane. However, this temperature difference is spread out over several pixels when the camera views the vane through the ZnSe infrared window at a non-normal angle. The thickness of the window displaces the image in the streamwise direction for images passing through at oblique angles.

Figure 6 shows the Nusselt number distribution based on a uniform heat flux. This Nusselt number distribution includes the corrections for radiation from the heated vane and conduction to the aluminum spar. The correction for radiation was small. At this Reynolds number the correction for conduction to the spar was also small. High temperature regions in figure 5 correspond to low Nusselt number regions in figure 6 .

Figure 7 shows the Nusselt distribution after correcting for the non uniformity in the electrical heat flux. Since there were variations in surface roughness on the vane surface, there would not be spanwise uniformity in the Nusselt number distribution for a uniform heat flux. Some of the spanwise non uniformity seen in this figure vane could be the result of non uniformity in the surface roughness. The pressure side view shows a low Nusselt number region on the pressure side of the leading edge. The heat transfer rises to the leading edge and beyond. The front suction view shows high heat transfer on the pressure side, a decrease in heat transfer, followed by an increase on the suction side of the vane. The suction rear view shows a fairly uniform level over much of the region away from the end bus bars. Midway along the surface of this view, and near midspan there is a high heat transfer region. Either high surface roughness or, 


\section{Pressure side}

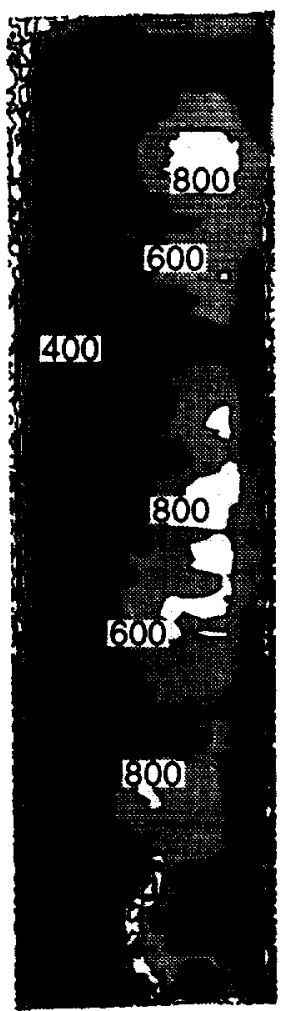

Suction - Front

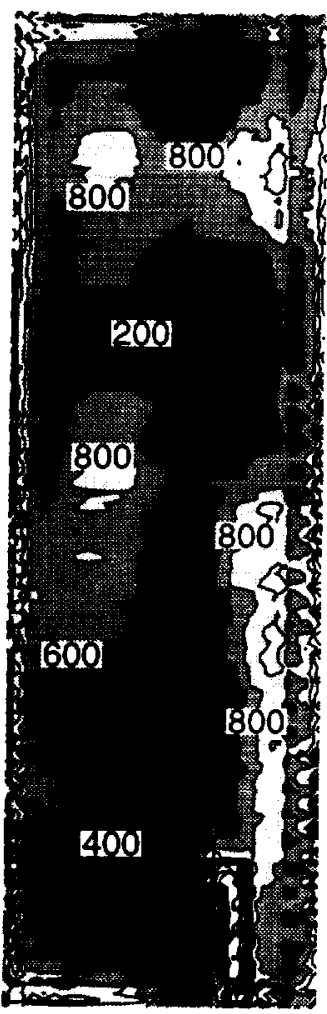

Fig. 7 Nusselt number - non uniform heat flux.

overestimating heat generation in this region could account for this apparent high heat transfer. An error in calculating the local value of $F$ causes a bias in the heat generation throughout the entire range of test conditions.

Midspan results. The data for each case were averaged over different fractions of the heated span. No significant variation in the spanwise averaged Nusselt number distribution was observed for averaging regions of 20 and $40 \%$ of the heated span.

$M_{2}=0.3$ results. Figure 8 shows the midspan heat transfer distribution for the different Reynolds numbers at the three vane exit Mach numbers, and for the two inlet turbulence intensities. Each part of the figure shows data for a single Mach number. Successive parts show data at low and high turbulence levels. High turbulence being the result of the upstream grid. For clarity, the pressure side window data have been offset on the plot by $s / C_{x}=-1$. In reality there is an overlap in the leading edge region. The two suction surface views have a gap between them, because the camera could not view a region upstream of the throat. The no grid data at $M_{2}=0.3$ shown in figure 8 a clearly shows suction surface transition moving forward as the Reynolds

\section{Suction - Rear}

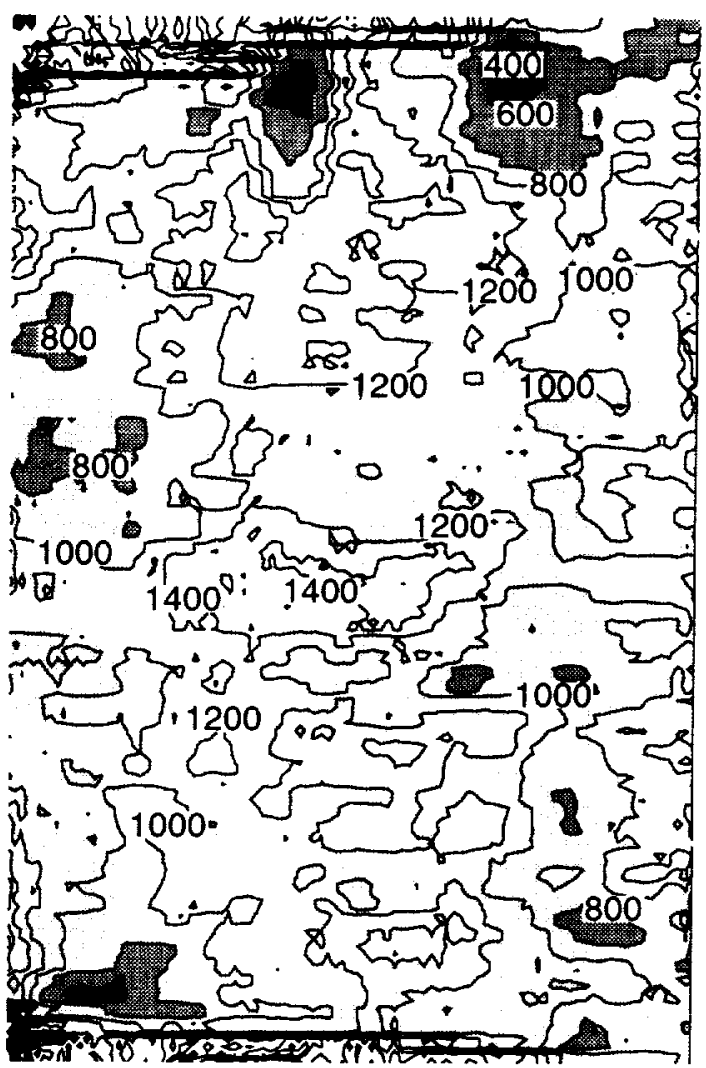

number increases. Data for the forward portion of the suction side show a heat transfer peak on the pressure side of the leading edge. $N u$ increases approaching the leading edge, $s / C_{x}=0$, from the pressure side, then decreases. This is followed by a rapid increase, and is most evident at higher Reynolds numbers.

The pressure side data do not show the peak leading edge heat transfer at $s / C_{x}=-1$ in the plot. The peak is over onto the suction surface. The surface on the far side of the leading edge is nearly tangential to the camera view. The discrepancy between the two views could be due to unaccounted variation in surface emissivity with viewing angle to the surface. In the overlap region the pressure side view heat transfer is somewhat higher.

Figure $8 \mathrm{~b}$ gives the Nusselt numbers for the same exit Mach number as in part (a), but with the grid installed. The presence of the grid increases the Nusselt number, even for the rear portion of the suction surface. For these tests, and those at higher Mach numbers, air was blown through the grid. Test were done. viewing the rear portion of the suction surface, with no grid air. The turbulence intensity varied significantly in the pitchwise direction for the unblown grid, (Boyle et al.(1998)). However, no significant Nusselt number differences were seen for the unblown grid test. 


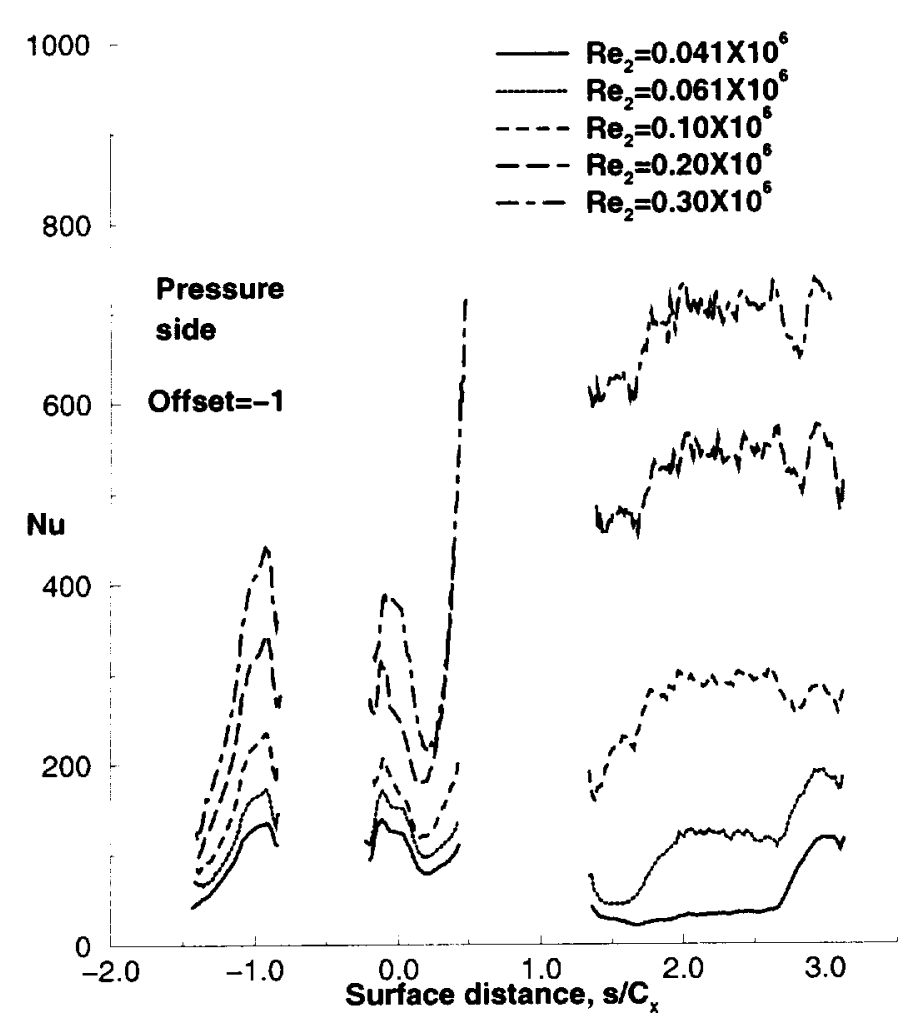

a) Nusselt number for $M_{2}=0.3$, No grid
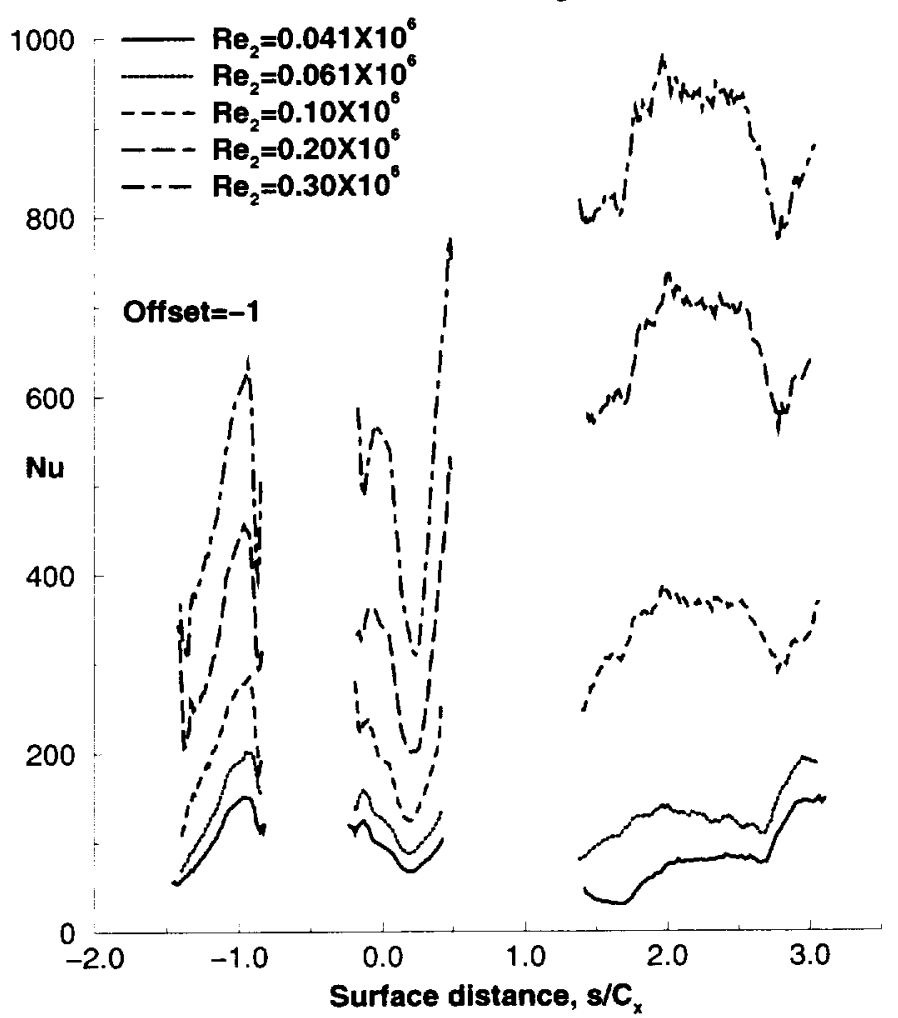

b) Nusselt number for $M_{2}=0.3$, Turbulence grid.

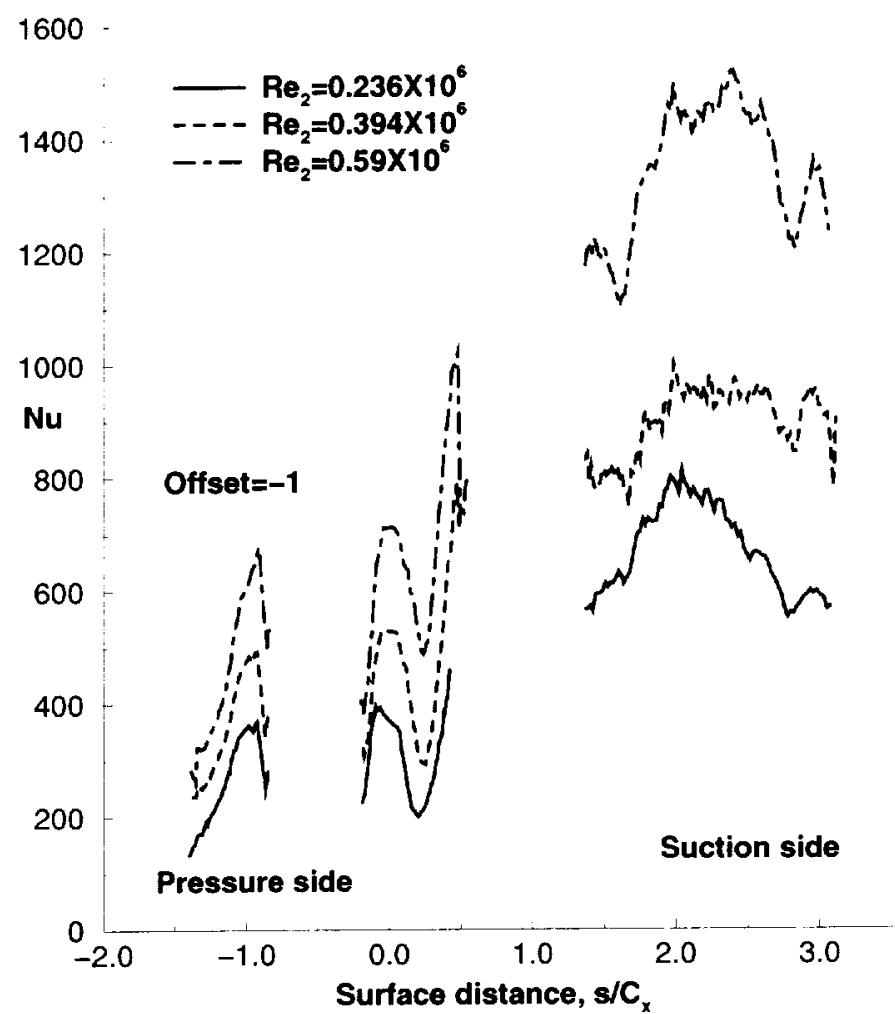

c) Nusselt number for $M_{2}=0.7$, No grid.

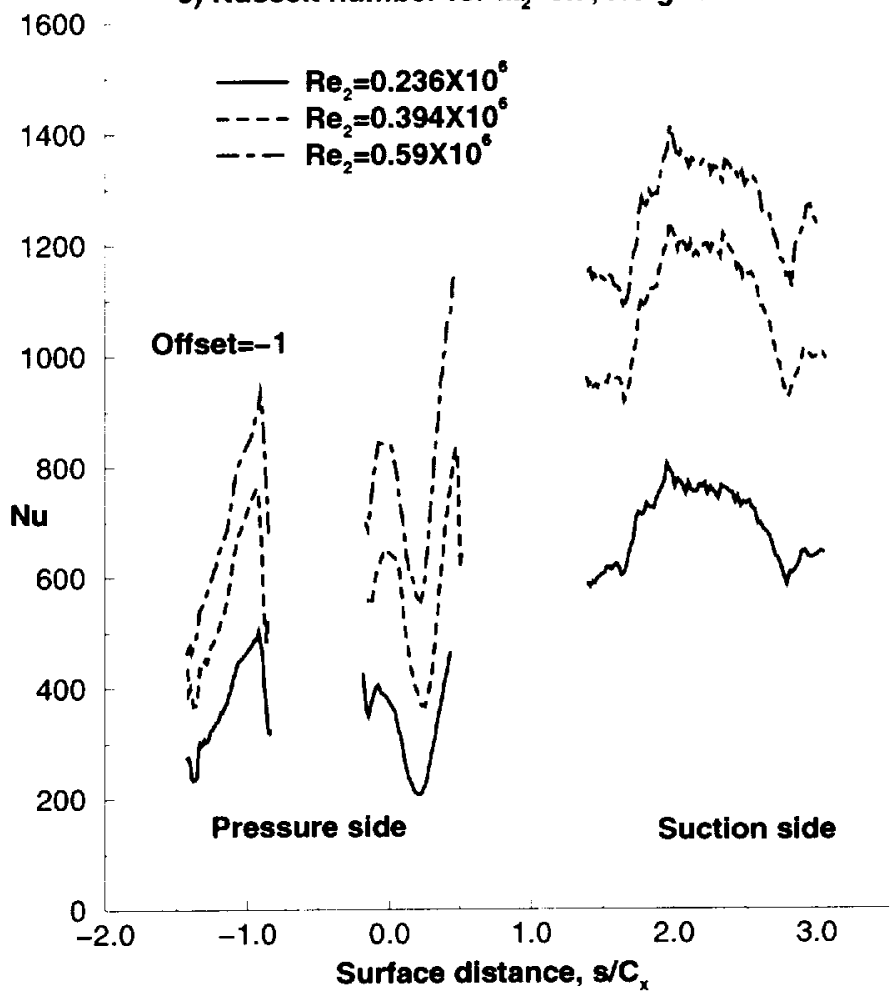

d) Nusselt number for $M_{2}=0.7$, Turbulence grid.

Fig. 8 Midspan Nusselt numbers. 


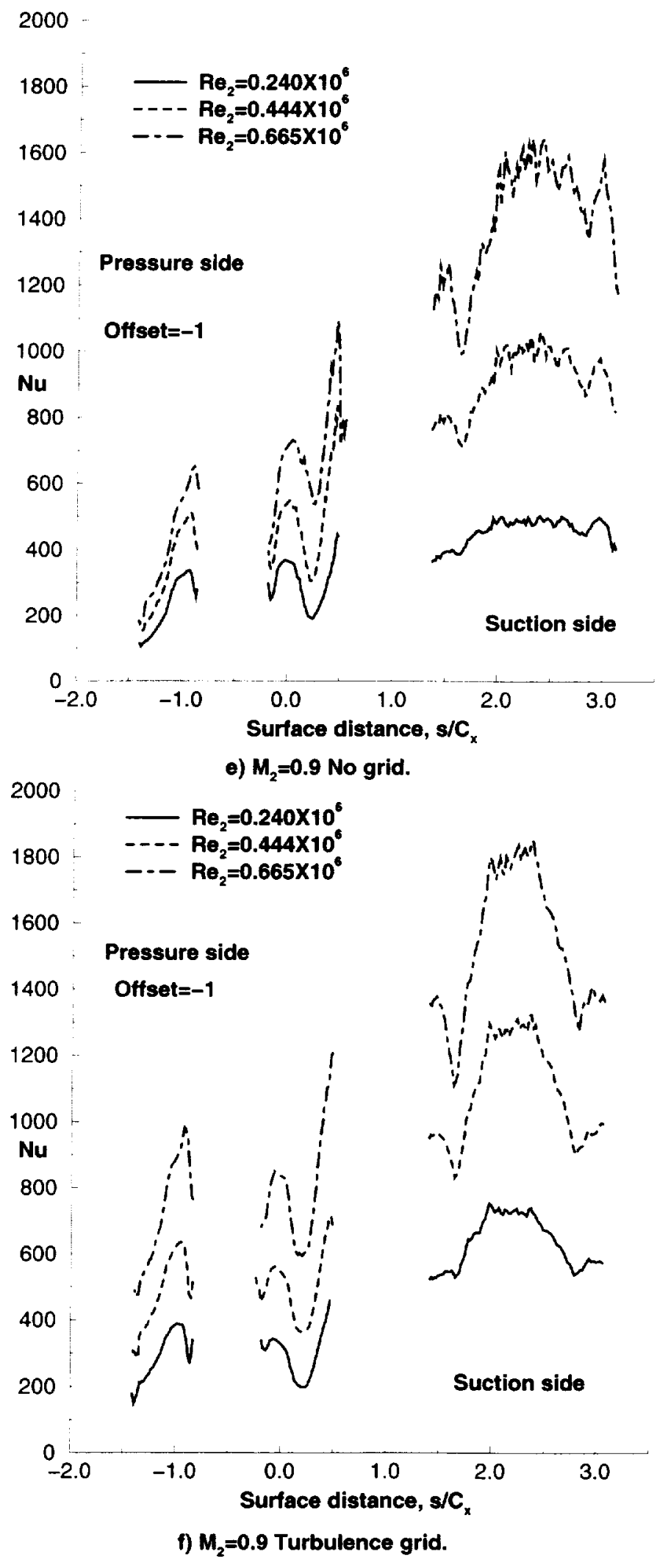

Fig. 8 Midspan Nusselt numbers, (cont.).
High $M_{2}$ results. At an exit Mach number of one, the flow chokes. so that the flow rate at constant Reynolds number does not significantly increase as the Mach number increases from 0.7 to 0.9 . As expected, the dat a obtained by viewing through the two forward windows at $M_{2}=0 . \bar{i}$ and at $M_{2}=0.9$ are similar to those for $M_{2}=0.3$. Even at the higher exit Mach numbers, the upstream Mach numbers are less than 0.3. For the two higher exit Mach number there is not as consistent an increase in suction side rear heat transfer with increased turbulence. What was observed. but is not evident in the figures, is an indication of a lower than expected recovery factor for a rough surface. It was observed that measurements with lower wall-to-gas temperature differences gave higher heat transfer rates. The recovery temperatures were calculated using a recovery factor of 0.89. A lower recovery factor, approximately 0.8 , resulted in Nusselt numbers for the rear portion of the suction surface independent of the wall-to-gas temperature difference. This is consistent with the observation of Hodge et. al.(1986) that a rough surface has a lower recovery factor than a smooth one.

Fixed point comparisons. Next. specific vane regions are examined to identify the effects of roughness on the vane heat transfer. Figure 9 shows the Frossling number. $F r$, at the vane stagnation point. If roughness had no effect. the low turbulence intensity Frossling number is expected to he in the range 0.85-1.0. Van Fossen et al.(1995). The data in figure $9 \mathrm{a}$, for low turbulence intensity, show increased Frossling number with increased Reynolds number. The low Frossling numbers, seen for the front suction side data at low Reynolds numbers, may be due to uncertainty in the position of the stagnation point in the camera view. If the leading edge line in the data reduction was not the true leading edge line, then the Frossling number would be less than the stagnation point value.

Figure 9b shows stagnation point heat transfer for the turbulence grid data. The grid resulted in a high turbulence level. measured as more than $13 \%$ approximately one axial chord upstream of the leading edge. The trend of an increased Frossling number with increase Reynolds number is similar to the no grid results. However, the slope, especially in the lower Reynolds number region, is greater. This figure also shows predictions using a correlation developed by Van Fossen et al.(1995) for a smooth leading edge. The correlation accounts for turbulence intensity and length scale effects on leading edge heat transfer. Primarily, because of the large turbulent length scale to leading edge diameter ratio, the correlation gives a relatively small increase in Frossling number. Over much of the Reynolds number 

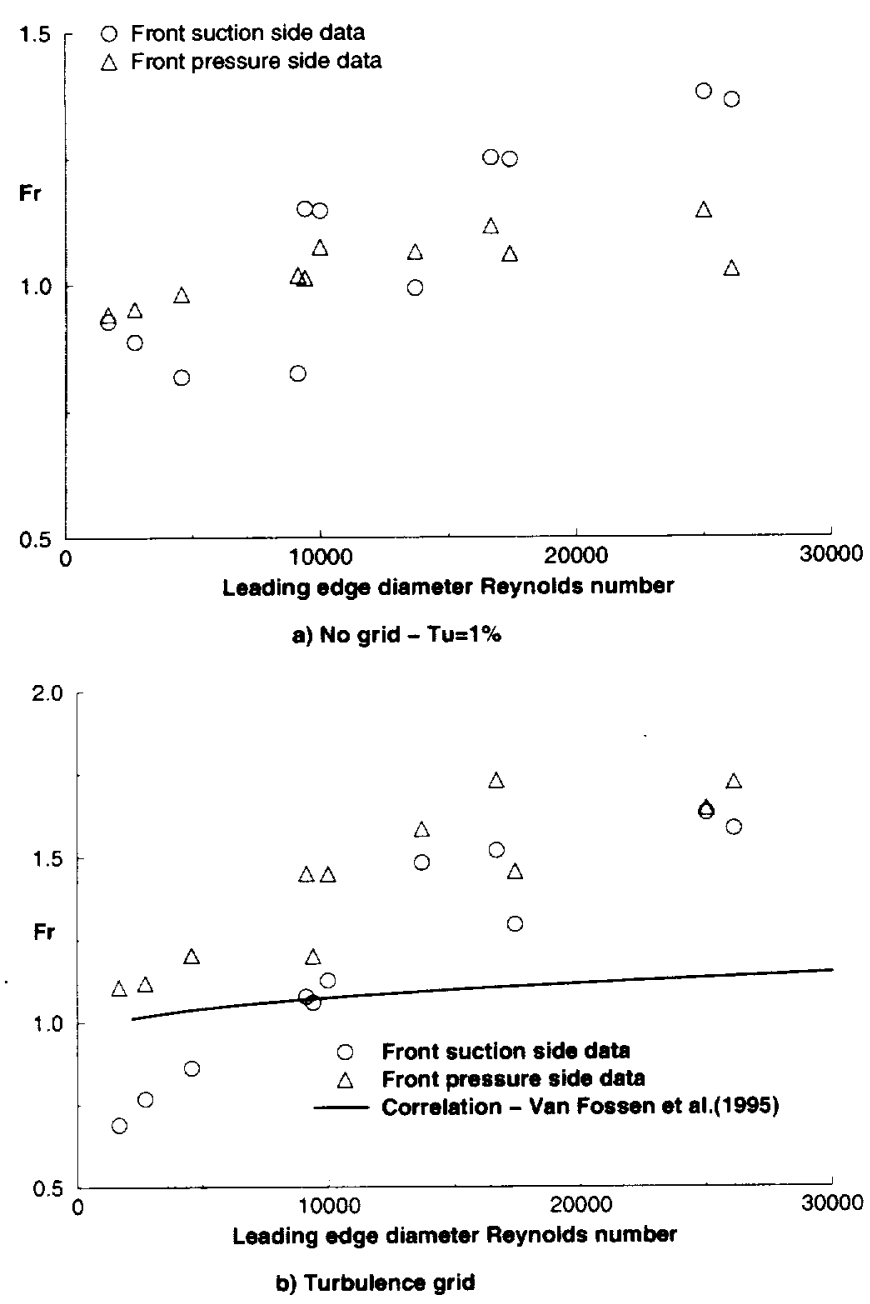

Fig. 9 Frossling number at vane stagnation point.

range, the effect of roughness on Frossling number is significantly greater.

Figure 10 shows the Stanton number at $s / C_{x}=2.5$. This location was chosen because the heat transfer coefficient is representative of the rear part of the suction surface. Results are presented in terms of Stanton number, $S t=N u / R \epsilon / P r$, since this quantity varies slowly with Reynolds number. In addition to the experimental data, correlation curves are shown. The turbulent Stanton number correlation for a smooth surface is shown along with results from a correlation given by hays and Crawford (1980) for rough surfaces. This correlation is:

$$
s t=\frac{C_{f} / 2}{P r_{t}+\sqrt{C_{f} / 2} / S t_{\mathrm{h}}}
$$

and

$$
S t_{\mathrm{h}}=C\left(\operatorname{Re} \frac{h_{\mathrm{EQ}}}{C_{\mathrm{x}}} \sqrt{\frac{C_{f}}{2}}\right)^{-0.2} P r^{-0.44}
$$

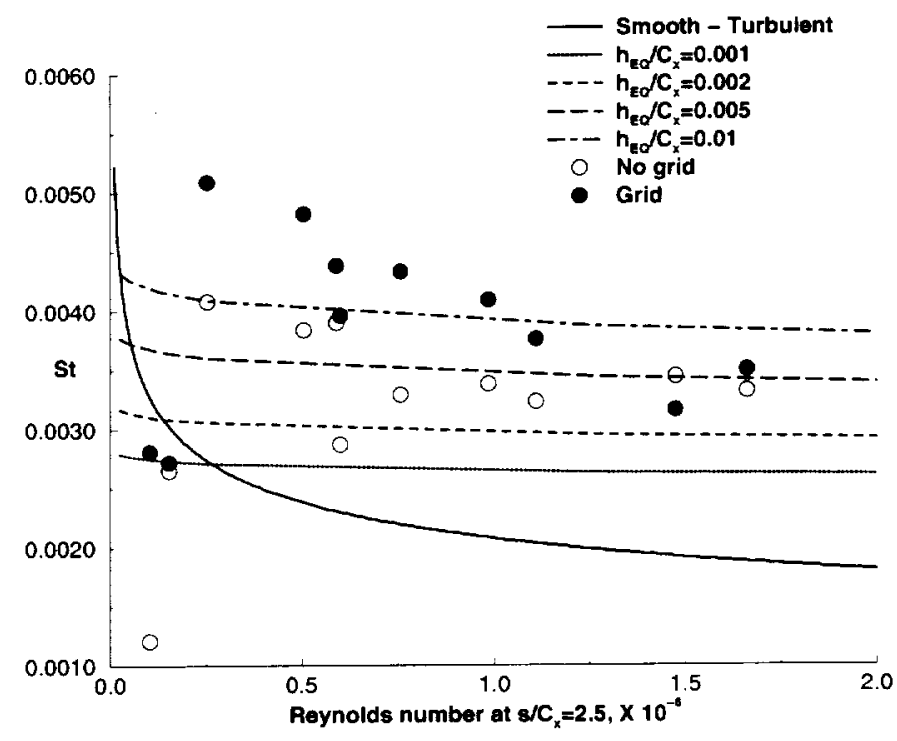

Fig. 10 Stanton number at $s / C_{x}=2.5$

The constant, $C$, which is a function of the roughness geometry is taken as 1 . While the appropriate value for this vane geometry is not known, the data of Pimenta et al.(1975) for closely packed spheres corresponded to a value of $C=1.0$. The Reynolds number is taken as $R c=R \epsilon_{2} s / C_{x} . \quad C_{f} / 2$ is determined from the rough surface correlation for a range of $h_{\mathrm{EQ}} / C_{\mathrm{x}}$ values. The turbulent Prandt number, $P r_{\mathrm{t}}$, was assumed to be 0.9 .

The lowest Reynolds number no grid case has a Stanton number below the turbulent corrclation. This value is consistent with a Stanton number for Jaminar flow. The data for the next highest Reynolds number is close to the smooth correlation for turbulent flow. At this Reynolds number, and lower, the flow appears to be hydraulically smooth, as it also does for the grid cases. The no grid cases show a rapid increase in Stanton number, followed by a decrease in Stanton number, eventually approaching the $h_{\mathrm{EQ}} / C_{\mathrm{x}}=0.005$ curve at high Reynolds numbers. Stanton numbers just after transition are typically higher than the turbulent value. As was mentioned earlier, the expected value for $h_{\mathrm{EQ}} / C_{\mathrm{x}}$ was 0.005 . With the turbulence grid in place, the trend shows higher Stanton numbers at lower Reynolds numbers, and a more negative slope of Stanton number versus Reynolds number. The grid Stanton numbers approach the no grid values at high Reynolds numbers.

Emissivity variations. As mentioned earlier, measurements of the surface emissivity gave a considerable amount of uncertainty. Among the factors which contributed to the emissivity uncertainty were the angle to the camera; the position on the vane: and uncertainty in the reference black paint emissivity. Figure 11 shows 


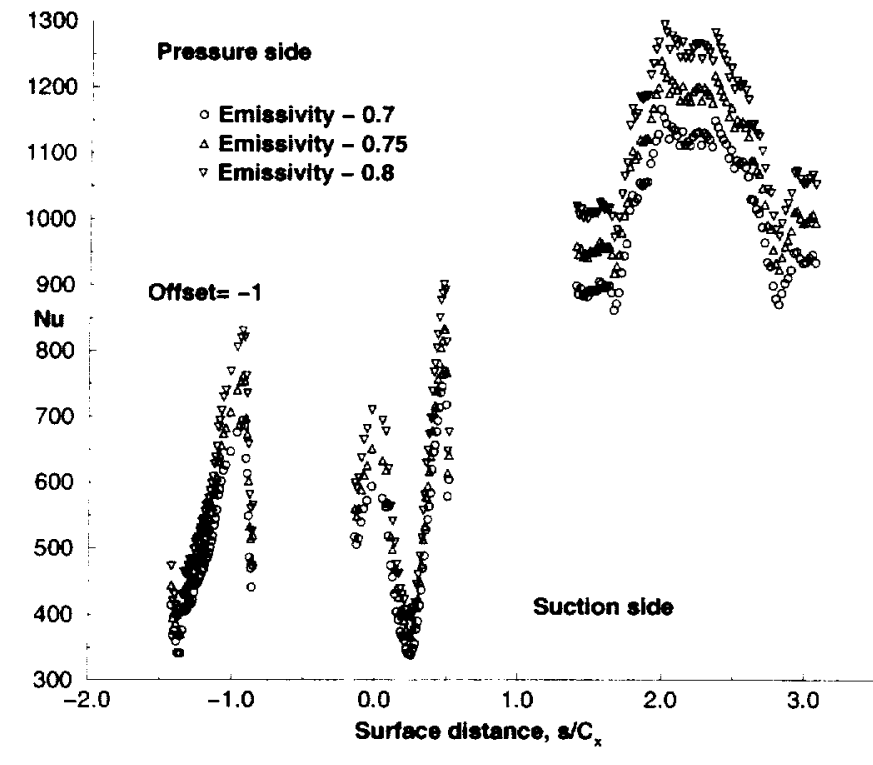

Fig. 11 Effect of emisstvity variaion, $R e_{2}=0.394 \times 10^{\circ}, M_{2}=0.7$, grid.

the midspan Nusselt number distribution for three values of the surface emissivity. The three values are the estimated value of $0.75 \pm 0.05$. Increasing the vane emissivity causes the vane temperature to decrease. This in turn causes the vane-to-gas temperature difference to decrease. While the Nusselt number does increase, as expected. the increase is not large. The number of symbols in each line are the number of pixels in the streamwise direction. The number of pixels per unit length were approximately the same in the spanwise and streamwise directions.

\section{CONCLUSIONS}

The experimental results showed that an infrared camera technique is a useful tool for measuring turbine heat transfer over the entire blade surface. Knowledge of surface emissivity and window transmission are important to achieving accurate results. Verifying the camera system output with a calibrated black body source. and verifying the agreement between the gas temperature measurement and surface temperatures measured with the infrared camera. results in accurate heat transfer even when the temperature differences are small. The portion of the blade surface for which the heat transfer is measured is controlled by optical access. The portion of the surface viewed through each window is determined by the adjacent blades. The fraction of the surface viewed is determined by the solidity as well as blade shape. Even though in this application the measurements were averaged to obtain the midspan heat transfer, spanwise as well as streamwise variations in surface temperatures were readily measured. This technique is applicable to measuring surface heat transfer resulting from three-dimensional flows.

Leading edge Frossling numbers increased with increasing Reynolds number. The increase was significantly greater than was expected from freestream turbulence effects. The trend in the low turbulence intensity dat a showed Frossling numbers approaching 1.3 at high Reynolds numbers. This is $30-40 \%$ greater than is expected for leading edge heat transfer of a smooth vane. When the inlet turbulence intensity was increased, the trend in leading edge Frossling number showed a higher initial slope. At high Reynolds numbers the Frossling number approached 1.T. The increased Frossling number at high turbulence was again greater than expected for a smooth surface, and approached $50 \%$ at high Reynolds numbers. The heat transfer augmentation due to roughness increased with Reynolds number throughout the range of test conditions.

The heat transfer on the rear portion of the suction surface was greater than would be expected for a smooth vane hy nearly a factor of two at high Reynolds numbers. For the low turbulence test cases, the ratio was less as the Reynolds number decreased. However. with a high turbulence intensity. the ratio renained close to two for Reynolds numbers of 101.000 and greater. Only for Reynolds numbers of 61.000 or less was the heat transfer consistent with that for a smooth surface. The estimated equivalent roughness height, $h_{\mathrm{EQ}}^{+}$was approximately 23 at a Reynolds number of 61.000 . This value of 23 corresponds to a transitionally rough equivalent height.

\section{REFERENCES}

Abuaf, N., Bunker, R.S., and Lee, C.P.. 1997. "Effects of Surface Roughness on Heat Transfer and Aerodynamic Performance of Turbine Airfoils," ASME paper 97-CT-10.

Baldauf, S.. Schulz. A., and Witting. S.. 1999, "High Resolution Measurements of Local Heat Transfer Coefficients By Discrete Hole Film Cooling," ASME paper 99-CiT-43.

Bammert, K., and Stanstede. H.. 1972, "Measurements Concerning the Influence of Surface Roughness and Profile Changes on the Performance of Gas Turbines," ASME Journal of Enginetering for Power. Vol. 94, pp. 207-213.

Bammert, K., and Stanstede. H., 1976, "Influences of Manufacturing Tolerances and Surface Roughness of Blades on the Performance of Turbines," ASME Journal of Engineering for Power. Vol. 98, pp. 29-36. 
Banks. B. A.. and Rutledge, S. K., 1982, "Ion Beam Sputter Deposited Diamondlike Films," NASA TM 82873.

Blair. M.F., 1994, "An Experimental Study of Heat Transfer in a Large-Scale Turbine Rotor Passage." ASME Journal of Turbomachinery. Vol. 116. pp. 113.

Boyle. R.J., Spuckler. (C.M., and Lucci, B.L., 2000 , "Comparison of Predicted and Measured Vane Rough Surface Heat Transfer," Proposed for presentation at the 45th ASME Gas Turbine and Aeroengine Technical Congress as 00-GT-021i.

Boyle. R.J.. Lucci, B.L., Verhoff, V. (i., Camperchioli, W.P., and La. H., 1998. "Aerodynamics of a Transitioning Turbine Stator Over a Range of Reynolds Numbers," ASME paper 98-GT-285.

Boyle, R.J., and Giel. P.W., 1995, "Three-Dimensional Navier-Stokes Heat Transfer Predictions for Turbine Blade Rows," AIAA Journal of Propulsion and Pouer. Vol. 11, No. 6, pp. 1179-1186.

Boynton. J.L.. Tabibzadeh, R., and Hudson. S.T., 1992, "Investigation of Rotor Blade Roughness Effects on Turbine Performance," ASME Journal of Turbomachinery. Vol. 115. pp. 614-620.

Braslow. A.L., 1960, "Review of the Effect of Distributed on Boundary Layer Transition," AGARD Report 254.

Burmeister. L.C. 1983, "Convective Heat Transfer," John Wiley and Sons, Inc. New York, p 544.

Chima, R.Y., 1996, "Application of the $k-\omega$ Turbulence Model to Quasi-Three-Dimensional Turbomachinery Flows." AIAA Journal of Propulsion and Pouer. Vol. 12, No. 6, pp. 1176-1179.

Dagnall. H., 1986, "Exploring Surface Texture," Second ed., Rank Taylor Hobson Limited, Leicester, England, p 158.

Dunn, M.G., Kim, J., Civinskas, K.C., and Boyle, R.J.. 1994, "Time-Averaged Heat Transfer and Pressure Measurements and (omparison with Prediction for a Two-Stage Turbine. ASME Journal of Turbomachinery. Vol. 116. pp. 14-22.
Hodge, B.K, Taylor, R.P., and Coleman, H.W., 1986. "An Investigation of Surface Roughness Effects on Adiabatic Wall Temperature," AIAA Journal. Vol. 24. No. 9. pp. 1560-1561.

Johnston, C.A.. Bogard. D.G., and McWaters, M.A.. 1999. "Highly Turbulent Mainstream Effects on Film cooling of a Simulated Airfoil Leading Edge." ASME paper 99-(iT-261.

Kays, W. M. and Crawford. Y. E.. 1980, "Convective Heat and Mass Transfer". Second Ed. McGraw-Hill Book Co.. New York. p 327.

Kind, R.J., Serjak, P.J., and Abbott. M.W.P., 1998, "Measurements and Prediction of the Effects of Surface Roughness on Profile Losses and Deviation in a Turbine (ascade," ASVE Journal of Turbomachinery. Vol. 120. pp. $20-2 \bar{\tau}$.

Pimenta, M.M., Moffatt, R.J., and Kays, W.M., 1995. "The Turbulent Boundary Layer: An Experimental Study of the Transport of Momentum and Heat with the Effect of Roughness," Rep. HMT-21. Dept. of Mechanical Engineering, Stanford Univ.

Sargent, S.R.. Hedlund, C.R., and Ligrani, P.M.. 1998. "An Infrared Thermography Imaging System for Convective Heat Transfer Measurements in Complex Flows," Meas. Sci. Technol. Vol. 9, pp 1974-1981.

Sweeney, P.C., and Rhodes, J.F., 1999, "An Infrared Technique for Evaluating Turbine Airfoil Cooling Designs," ASME paper 99-CT-142.

Tarada, F., 1987, "Heat transfer to Rough Turbine Blading," PhD thesis, University of Sussex. England

Tarada, F., and Suzuki, M., 1993, "External Heat Transfer Enhancement to Turbine Blading Due to Surface Roughness," ASME paper 93-GT-74.

Taylor, R.P., 1990, "Surface Roughness Measurements on Gas Turbine Blades," ASME Journal of Turbomachinery. Vol. 112, pp. 175-180.

Van Fossen. G.J., Simoneau, R.J., and Ching, C.Y., 1995. "Influence of Turbulence Parameters, Reynolds Number, and Body Shape on Stagnation Region Heat Transfer". ASME Journal of Heat Transfer. Vol. 11T. pp. $597-603$. 
Public reporting burden for this collection of information is estimated to average 1 hour per response, including the time for reviewing instructions, searching existing data sources. gathering and maintaining the data needed, and completing and reviewing the collection of information. Send comments regarding this burden estimate or any other aspect of this collection of intormation, including suggestions for reducing this burden, to Washington Headquarters Services. Directorate for Information Operations and Reports. 1215 Jefferson Davis Highway. Suite 1204, Artington, VA 22202-4302, and to the Office of Management and Budget, Paperwork Reduction Project (0704-0188), Washington, DC 20503.

\begin{tabular}{l|l|l|} 
1. AGENCY USE ONLY (Leave blank) & 2. REPORT DATE & 3. REPORT TYPE AND DATES COVERED
\end{tabular}

\section{TITLE AND SUBTITLE}

August 2000

Infrared Low Temperature Turbine Vane Rough Surface Heat Transfer Measurements

6. AUTHOR(S)
Memorandum

R.J. Boyle, C.M. Spuckler, B.L. Lucci, and W.P. Camperchioli

\section{PERFORMING ORGaNIZATION NAME(S) AND ADDRESS(ES)}

National Aeronautics and Space Administration John H. Glenn Research Center at Lewis Field Cleveland, Ohio 44135-3191

9. SPONSORING/MONITORING AGENCY NAME(S) AND ADDRESS(ES)

National Aeronautics and Space Administration

Washington, DC 20546-0001
WU-523-26-13-00

8. PERFORMING ORGANIZATION REPORT NUMBER

E-12339

10. SPONSORINGMONITORING AGENCY REPORT NUMBER

NASA TM-2000-210220

ASME-2000-GT-0216

\section{SUPPLEMENTARY NOTES}

Prepared for the 45th International Gas Turbine and Aeroengine Technical Congress sponsored by the American Society of Mechanical Engineers, Munich, Germany, May 8-11, 2000. Responsible person, R.J. Boyle, organization code 5820, (216) 433-5889.

\section{2a. DISTRIBUTIONVAVAILABILITY STATEMENT}

12b. DISTRIBUTION CODE

Unclassified - Unlimited

Subject Category: 34

Distribution: Nonstandard

This publication is available from the NASA Center for AeroSpace Information, (301) 621-0390.

13. ABSTRACT (Maximum 200 words)

Turbine vane heat transfer distributions obtained using an infrared camera technique are described. Infrared thermography was used because noncontact surface temperature measurements were desired. Surface temperatures were $80^{\circ} \mathrm{C}$ or less. Tests were conducted in a three vane linear cascade, with inlet pressures between 0.14 and 1.02 atm., and exit Mach numbers of $0.3,0.7$, and 0.9 , for turbulence intensities of approximately 1 and $10 \%$. Measurements were taken on the vane suction side, and on the pressure side leading edge region. The designs for both the vane and test facility are discussed. The approach used to account for conduction within the vane is described. Midspan heat transfer distributions are given for the range of test conditions.

\begin{tabular}{|l|l|l|}
\hline $\begin{array}{l}\text { 14. SUBJECT TERMS } \\
\text { Turbine heat transfer; Surface roughness }\end{array}$ \\
\begin{tabular}{c|c|c|} 
17. SECURITY CLASSIFICATION \\
OF REPORT \\
Unclassified
\end{tabular} & $\begin{array}{c}\text { 18. SECURITY CLASSIFICATION } \\
\text { OF THIS PAGE } \\
\text { Unclassified }\end{array}$ & $\begin{array}{c}\text { 19. SECURITY CLASSIFICATION } \\
\text { OF ABSTRACT } \\
\text { Unclassified }\end{array}$ \\
\hline
\end{tabular}

15. NUMBER OF PAGES 21

16. PRICE CODE

$\mathrm{A03}$
20. LIMITATION OF ABSTRACT 
